\title{
A combination of biochar and regulated deficit irrigation improves tomato fruit quality: A comprehensive quality analysis
}

\author{
Larona Keabetswe ${ }^{1 *}$, Guang Cheng Shao ${ }^{1}$, Jintao Cui ${ }^{1,2}$, \\ Jia Lü, Tebogo Stimela ${ }^{3}$

\begin{abstract}
${ }^{1}$ Key Laboratory of Efficient Irrigation-Drainage and Agricultural Soil-Water Environment in Southern China Ministry of Education, College of Agricultural Engineering Hohai University, Nanjing 210098, P. R. China ${ }^{2}$ Institute for Sustainable Food Systems and Department of Agricultural and Biological Engineering University of Florida, Gainesville, FL 32611, USA

${ }^{3}$ Department of Crops and Soil Science Botswana University of Agriculture and Natural Resources, Gaborone, Botswana
\end{abstract}

\begin{abstract}
Quality of fresh produce is the most critical issue in the economics of a vegetable enterprise. In order to investigate the effect of biochar amendment and deficit irrigation on tomato fruit quality, experimental research was conducted under a rain shelter in southern China during the 2017 and 2018 growing seasons. The experiment consisted of five treatments. Crops were irrigated to $100 \%$ of field water capacity at all growth stages as treatments $\mathrm{T} 1$ and $\mathrm{T} 2$. The other treatments received $30 \%$ less irrigation water than $\mathrm{T} 2$ when its soil water content reached $70 \%$ of field capacity, and were designated as treatments $\mathrm{T} 3$, T4 and T5, applied at the vegetative (stage I), flowering and fruit development (stage II), and fruit ripening (stage III) stages, respectively. Treatment T1 included no biochar, while the other treatments included $10 \%$ biochar by weight. The results showed that the total soluble solids (TSS) content, sugar-to-acid ratio (SAR), vitamin C (VC) content, and colour index (CI) increased in the deficit irrigation treatments depending on the phenological stage, the fruit ripening stage in particular. Meanwhile, single fruit weight was significantly $(p<0.05)$ reduced by water deficit at stages II and III, subsequently affecting the total fruit yield. Biochar improved soil moisture conservation and had a positive effect on fruit quality as evidenced by better single quality attributes $(p<0.05)$ of T2 over T1. The GRA and TOPSIS appraisal methods were used to conduct the comprehensive quality analysis. Eventually, treatment T5 ranked the best in both seasons, and this was also confirmed by the combinational evaluation method.
\end{abstract}

Key words: comprehensive appraisal method, irrigation regime, phenological stage, quality attributes, soil amendment, Solanum lycopersicon L., water stress

\section{INTRODUCTION}

As of recent, the need for quality assurance of fresh produce for the market has been growing steadily, with an increasing demand for high quality fresh fruits, mainly from the new export markets. The tomato (Solanum lycopersicon L.) is one of the most popular crop plants, and it is widely planted

*Corresponding author. 
across the world (Jensen et al., 2010). Fresh tomato fruit is an important component of human diet as it is a source of nutritional elements and antioxidants that are beneficial to health (Wang et al., 2011; Shao et al., 2015). In recent years, tomato consumption has been recommended for inclusion in human diet, as it has the ability to suppress the risk of getting some diseases (Wang et al., 2015).

Among the factors affecting tomato fruit quality, irrigation management or strategy, in particular deficit irrigation, is essential to improving quality. It is a water-saving approach whereby crops are exposed to application of water below their evapotranspiration requirements for a certain period of time (Djurovic et al., 2016). When deficit irrigation is applied appropriately, it tends to increase the internal fruit quality attributes such as the concentrations of phenolics, beta-carotenoids, lycopene, and vitamin $\mathrm{C}$, and also the sugar/acid ratio, while lowering the colour hue angle (Favati et al., 2009). Although deficit irrigation helps to improve quality, it has a negative effect on yield (Cantore et al., 2016), and for that reason soil amendments such as biochar can be used to alleviate that effect (Usman et al., 2016).

The ability of biochar to enhance yield might be attributed to its complementary properties and its capacity to retain soil moisture. On the other hand, the combination of biochar with deficit irrigation can supply supplementary substrates to the soil to mitigate water stress (Agbna et al., 2017). Some studies have indicated that biochar does not only improve soil physical status but also contributes to significant increases in the availability of macronutrients that are essential for improving fruit quality. The availability of organic matter and other nutrients increases with biochar addition, which can be attributed to the creation of an environment conducive to the propagation of microorganisms which are a source of nutrients (Steiner, 2007; Warnock et al., 2007).

Tomato fruit quality is a comprehensive concept which consists of a sum of interactions among the different individual quality attributes (Wang et al., 2011). There are various methods that have been used to evaluate tomato quality, for example, the Technique for Order Preference by Similarity to Ideal Solution (TOPSIS), Grey Relational Analysis (GRA), and Principal Component Analysis (PCA) (Wang, 2011), with each having its main feature and applicability related to a certain kind of requirement. However, all these methods are begun with the Analytic Hierarchy Process (AHP) (Zhu and $\mathrm{Xu}, 2014)$ for calculating the weight of each index. The AHP is a powerful technique for decision making, which depends on people's intrinsic ability to structure their perceptions.

However, there have been relatively few studies that applied these techniques to evaluate tomato quality. Furthermore, many studies have been carried out to evaluate the response of tomato yield and quality to water stress, but with less emphasis on a comprehensive quality assessment. So, the objective of this study was to explore the comprehensive quality response of tomato fruit to biochar amendment and regulated deficit irrigation using TOPSIS and GRA, and then use the combinational evaluation method to find a suitable treatment with the maximum quality output.

\section{MATERIAL AND METHODS}

\section{Experimental site}

The research study was conducted during the tomato growing seasons of 2017 and 2018 at the Key Laboratory of Efficient Irrigation-Drainage and Agricultural Soil-Water Environment in Southern China ( $31^{\circ} 57^{\prime} \mathrm{N}, 118^{\circ} 50^{\prime} \mathrm{E}$, and $144 \mathrm{~m}$ above MSL). The climatic conditions of the study area are those of humid subtropics, which are influenced by the monsoon climate of East Asia. The experiment was carried out under an open-end rain shelter with a planting area of $140 \mathrm{~m}^{2}$. The temperature and relative humidity inside the rain shelter were recorded with time loggers, and they ranged from 18 to $39^{\circ} \mathrm{C}$ and 40 to $95 \%$, respectively. At the fifth leaf stage, tomato (var. Jinfen M-5) seedlings were transplanted into plastic pots $(0.15 \mathrm{~m}$ in diameter and $1.2 \mathrm{~m}$ in height). Clay loam soil was used for this experiment, and the mean dry bulk density and field water capacity (FC) at the 0-30 $\mathrm{cm}$ depth were $1.36 \mathrm{~g} \mathrm{~cm}^{-3}$ and $0.46 \mathrm{~cm}^{3} \mathrm{~cm}^{-3}$, respectively. The organic matter content of the soil was $0.71 \%$, with a pH of 6.1. Doses of compound fertilizers (N 15\%, $\mathrm{P}_{2} \mathrm{O}_{5} 15 \%, \mathrm{~K}_{2} \mathrm{O} 15 \%$ ) were applied as basal dressing at a rate of $500 \mathrm{~kg} \mathrm{ha}^{-1}$ before transplanting.

\section{Biochar amendment}

The biochar used for this experiment was produced from wheat straw pyrolyzed at $350-550^{\circ} \mathrm{C}$ in a vertical kiln made of refractory bricks by Sanli New Energy Company, Henan Province, China. With such a technology, $30 \%$ of wheat straw dry matter would be expected to be converted to biochar (Pan et al., 2011; Liu et al., 2014; Agbna et al., 2017). It was ground into fine powder and mixed thoroughly with soil before being used for filling 
the pots at $10 \%$ by weight. The biochar amendment had an initial $\mathrm{pH}$ of 9.9 , organic matter content of $467.2 \mathrm{~g} \mathrm{~kg}^{-1}$, total $\mathrm{N}$ of $5.9 \mathrm{~g} \mathrm{~kg}^{-1}$, total $\mathrm{P}$ of 14.43 $\mathrm{g} \mathrm{kg}^{-1}$, total $\mathrm{K}$ of $11.5 \mathrm{~g} \mathrm{~kg}^{-1}$, and cation exchange capacity of $21.7 \mathrm{c} \mathrm{mol} \mathrm{kg}$.

\section{Experimental design and irrigation regimes}

Five treatments replicated three times were allocated in a completely random design under a rain shelter. The plants were irrigated to $100 \%$ of field water capacity for all growth stages in treatments $\mathrm{T} 1$ and $\mathrm{T} 2$. The experimental treatments were based upon the growth stages: the vegetative stage (stage I) was from transplanting to the first fruit set; the flowering and fruit development stage (stage II) was from the first fruit set to the beginning of fruit maturity; and the fruit ripening stage (stage III) was from the beginning of fruit maturity to the final harvest. Further details can be found in Chen et al. (2013). Three deficit irrigation treatments received $30 \%$ less water than $\mathrm{T} 2$, but at different stages: treatment T3 during stage I, T4 during stage II, and T5 during stage III. Except for the stages that were subjected to water stress, irrigation amounts were the same as for treatment T2 (Tab. 1). Irrigation was applied when the soil moisture content of T2 reached $70 \%$ of field water capacity. There was no biochar amendment for treatment $\mathrm{T} 1$, while the other treatments included biochar amendment at $10 \%$ by weight. After transplanting, soil moisture was monitored regularly at four-day intervals using the gravimetric method at $10 \mathrm{~cm}$ increments to a depth of $30 \mathrm{~cm}$.

\section{Crop water use}

In order to approximate crop water use, the soilwater balance approach was used by observing soil moisture change. There was no ground water contribution, as pots were used, and no precipitation or runoff. Drainage outlets of the pots were closed for the entire growing season, so there was no drainage influence, and thus Eq. 1 was used:

$$
E T=I+\Delta W
$$

where $E T$ was the actual crop water use $(\mathrm{mm}) ; I$ was the irrigation amount $(\mathrm{mm})$; and $\Delta W$ was the change in moisture content $(\mathrm{mm})$.

\section{Measurements of yield and quality}

During the fruit ripening period, fruits were harvested to determine individual fruit weight and fresh fruit yield, and for subsequent quality measurements. For each harvest, the weight, volume, shape and colour of all the harvested fruits from each treatment were determined. The shape index was calculated using the ratio of vertical to horizontal diameters, which were measured with vernier callipers. A spectrophotometer (SP60, X-rite, Incorporated, MI, USA) was used to measure the colour of each fruit, whereby average values of the colour space coordinates $\mathrm{a}, \mathrm{b}$ and $\mathrm{L}$ were obtained and then converted into the colour index with the following equation:

$$
\mathrm{CI}=\frac{2000 a}{L \sqrt{a^{2}+b^{2}}}
$$

where CI is the fruit colour index; $L$ is the brightness varying from black to white; $b$ and $a$ are scales varying from green to red and blue to yellow, respectively.

Twenty tomatoes were randomly selected from marketable fruits for measurements of fruit chemical quality traits [Total Soluble Solids (TSS); Organic Acid (OA); Vitamin C (VC); Sugar/Acid ratio (SAR)], as described by Shao et al. (2015).

\section{Comprehensive quality appraisal}

Analytic Hierarchy Process ( AHP)

Specific steps of the AHP method are described by Wang (2011) and Wang et al. (2011). In the current

Table 1. Description of tomato growth stages and irrigation treatments

\begin{tabular}{ll}
\hline Growth stage / treatment & Description \\
\hline All stages / T1 & $\begin{array}{l}\text { Irrigation lower limit is } 70 \% \text { of field water capacity for all growth stages, without biochar } \\
\text { amendment }\end{array}$ \\
All stages / T2 & $\begin{array}{l}\text { Irrigation lower limit is } 70 \% \text { of field water capacity for all growth stages, with biochar amendment } \\
\text { Stage I / T3 }\end{array}$ \\
& $\begin{array}{l}30 \% \text { less water than in T2 was applied at the vegetative stage at the time of irrigation, with biochar } \\
\text { amendment } \\
\text { Stage II / T4 }\end{array}$ \\
irrigation, with biochar amendment \\
Stage III / T5 & $\begin{array}{l}30 \% \text { less water than in T2 was applied at the fruit ripening stage at the time of irrigation, with } \\
\text { biochar amendment }\end{array}$ \\
\hline
\end{tabular}

*Irrigation upper limit for T1 and T2 is $100 \%$ field water capacity 


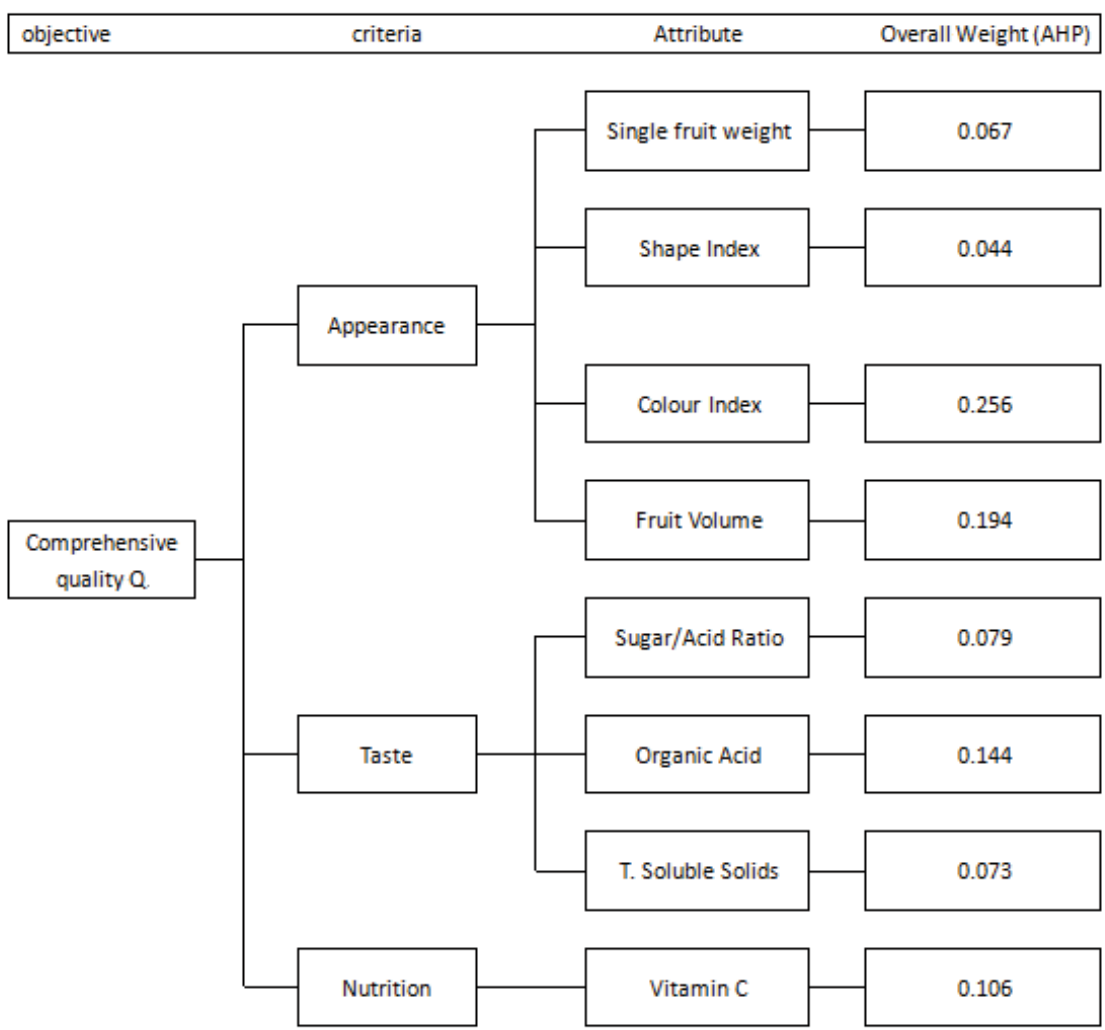

Figure 1. Evaluation hierarchy of tomato comprehensive quality and the overall weights of the AHP method. (Source: Shao et al. 2015, the same study site as that of the current study)

study, the pair-wise comparison matrix and final weights from the AHP were adopted from Shao et al. (2015), as in Figure 1.

\section{TOPSIS analysis}

$$
A=\left[\begin{array}{cccc}
a_{11} & a_{12} & \cdots & a_{1 n} \\
a_{21} & a_{22} & \cdots & r_{2 n} \\
\vdots & \vdots & \ddots & \vdots \\
a_{m 1} & a_{m 2} & \cdots & a_{n m}
\end{array}\right]
$$

The matrix is then normalized to form $R=\left(r_{i j}\right)_{m x n}$, where: $r_{i j}=x_{i j} / \sum_{i=1}^{m} x_{i j}, i=1,2, \ldots, \mathrm{m}, j=1,2, \ldots, \mathrm{n}$, $x_{i j}$ is the measured value of $j$ in alternatives $A_{i}$. In order to determine the worst $\left(A^{-}\right)$and the best $\left(A^{+}\right)$ alternatives, the following equations are used:

$$
\begin{aligned}
A^{+} & =\left\{r_{1}^{+}, r_{2}^{+}, \ldots, r_{j}^{+}, \ldots, r_{n}^{+}\right\} \\
& =\left\{\left(\max _{i} r_{i j} \mid j \in j_{+}\right),\left(\min _{i} r_{i j} \mid j \in j_{-}\right) \mid i=1,2, \ldots, m\right\} \\
A^{-} & =\left\{r_{1}^{-}, r_{2}^{-}, \ldots, r_{j}^{-}, \ldots, r_{n}^{-}\right\} \\
& =\left\{\left(\min _{i} r_{i j} \mid j \in j_{+}\right),\left(\max _{i} r_{i j} \mid j \in j_{-}\right) \mid i=1,2, \ldots, m\right\}
\end{aligned}
$$

where $j_{+}$is associated with better quality and $j_{-}$with the worst. The distance of the best $\left(d_{i}^{+}\right)$and the worst $\left(d_{i}^{-}\right)$solutions between alternatives $A_{i}$ and the ideal solution $\left(A^{+}\right.$or $\left.A^{-}\right)$is calculated by weighted Euclidean distances as follows:

$$
\begin{aligned}
& d_{i}^{+}=\sqrt{\sum_{j=1}^{n} w_{j}\left(r_{i j}-r_{j}^{+}\right)^{2}}, \quad i=1,2, \ldots, m \\
& d_{i}^{-}=\sqrt{\sum_{j=1}^{n} w_{j}\left(r_{i j}-r_{j}^{-}\right)^{2}}, \quad i=1,2, \ldots, m
\end{aligned}
$$

where $w_{j}$ is the overall weight of the $j$ th attribute with respect to the comprehensive quality, which comes from the AHP method. The comprehensive quality of different treatments is then ranked using the following equation:

$$
Q_{i}=\frac{d_{i}^{-}}{d_{i}^{+}+d_{i}^{-}}, \quad i=1,2, \ldots, m, 0 \leq Q_{i} \leq 1
$$

Note: $Q_{i}=1$ if, and only if, the alternative solution has the best condition, and $Q_{1}=0$ if, and only if, the alternative solution has the worst outcome.

\section{Grey relational analysis (GRA)}

The experimental data of tomato quality parameters were initially normalized and the normalization $x_{i j}$ for the quality characteristic is expressed as 


$$
x_{i j}=\frac{y_{i j}-\min _{j} y_{i j}}{\max _{j} y_{i j}-\min _{j} y_{i j}}
$$

where $y_{i j}$ is the original quality trait, $i=1,2, \ldots, m$, $j=1,2, \ldots, n$. The grey relational coefficients $\xi_{i j}$ were calculated using Eq. 10:

$$
\xi_{i j}=\frac{\min _{i} \min _{j}\left|x_{i}^{0}-x_{i j}\right|+\zeta \max _{i} \max _{j}\left|x_{i}^{0}-x_{i j}\right|}{\left|x_{i}^{0}-x_{i j}\right|+\zeta \max _{i} \max _{j}\left|x_{i}^{0}-x_{i j}\right|}
$$

where $x_{i}^{0}$ is the ideal normalized result for the $i$ th quality characteristic and $\zeta \in[0,1]$ is a distinguishing coefficient which is normally set at 0.5 . The weighting sum of the coefficients is defined as the grey relational grade $R_{i}^{*}$, which is given by

$$
R_{i}^{*}=\sum_{i=1}^{m} w_{x} \xi_{i j}
$$

where $w_{x}$ is the final weight of the ith quality trait, obtained from the AHP method.

\section{Combinational evaluation}

The first step in the combinational evaluation method is to determine the Spearman correlation coefficients by computing the rank of comprehensive and single quality indices of different treatments from GRA and TOPSIS. The Spearman correlation coefficients are expressed as

$$
\rho_{s}=1-\frac{6 \sum d_{i}^{2}}{n\left(n^{2}-1\right)}
$$

where $d_{i}$ is the difference between the ranks of comprehensive and single quality indices of different treatments and $\mathrm{n}$ is the number of observations. The weight for each method was then calculated with

$$
w_{k}=\frac{\rho_{k}}{\sum_{m}^{j=1} \rho_{j}}, \quad k=1,2, \ldots, m, j=1,2, \ldots, m
$$

where $\rho_{k}$ is the summation of Spearman correlation coefficients from each method, and finally the combinational value $C_{i}$ was computed with Eq. 14:

$$
C_{i}=\sum_{j=1}^{m} w_{j} z_{i j}
$$

where $z_{i j}$ is either the value $Q_{i}^{*}$ or $R_{i}^{*}$ of TOPSIS or GRA methods, respectively.

\section{Statistical analysis}

All statistical analyses involved in this study were performed using the Statistical Product and Service Solutions (SPSS) version 16.0 software (SPSS Inc., USA). The data were evaluated using oneway analysis of variance (ANOVA), and the least significant differences (LSD) test at $p \leq 0.05$ was used to assess statistical differences between the means of each treatment.

\section{RESULTS}

\section{Soil moisture depletion}

The trends for soil moisture content during both seasons were similar for the different irrigation treatments (Figs 2 and 3). The soil moisture content in treatment $\mathrm{T} 2$ was higher than that in treatment $\mathrm{T} 1$ in both growing seasons despite the soil being subjected to the same irrigation regime. This difference could be attributed to biochar
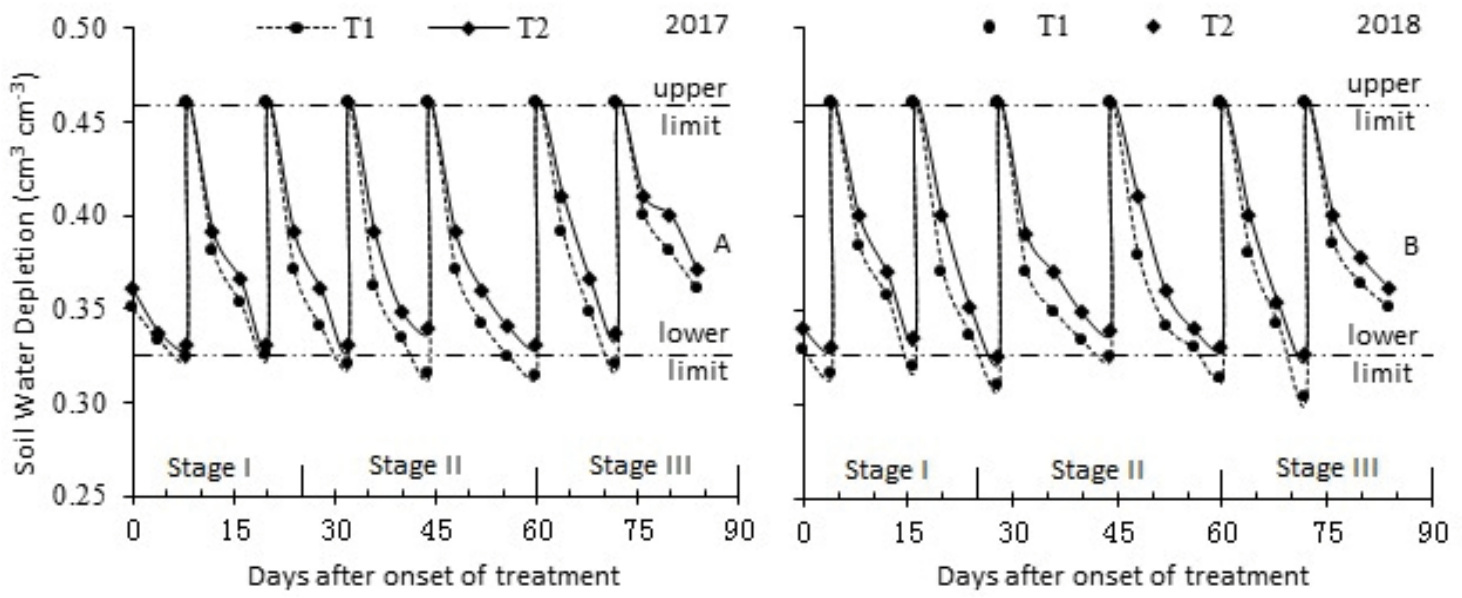

Figure 2. Trends of soil water depletion $(0-30 \mathrm{~cm}$ depth) of treatments with the same irrigation regime (100\% FC) during the cropping cycle in the 2017 (A) and 2018 (B) seasons. The upper constant horizontal dash line indicates the upper irrigation limit, 100\% field capacity. The lower constant horizontal dash line indicates the lower irrigation limit, $70 \%$ field capacity. T1 included no biochar amendment and $\mathrm{T} 2$ included biochar at $10 \%$ by weight. The treatment symbols are the same as in Table 1 
through its complementary characteristics of modifying soil pore size distribution associated with aggregation improvements. The reduction in irrigation during any growth stage decreased soil moisture. The plants that were subjected to water stress showed a decrease in ET (Tab. 2). The ET mean values of deficit irrigation treatments did not show a significant difference $(p<0.05)$ except for treatment T5 in the 2018 season. The lowest ET was obtained for treatment T5 at stage III in both seasons.

\section{Total fruit yield and water use efficiency}

There is a direct relationship between tomato fruit quality and total yield through the average single fruit weight. This quality trait largely determines the final outcome of total yields of crops. The fruit yields obtained at various growth stages during the two growing seasons are presented in Table 2. For both seasons, the largest value of crop yield was recorded under full irrigation with the biochar amendment (treatment T2), and the statistical difference in relation to the control was
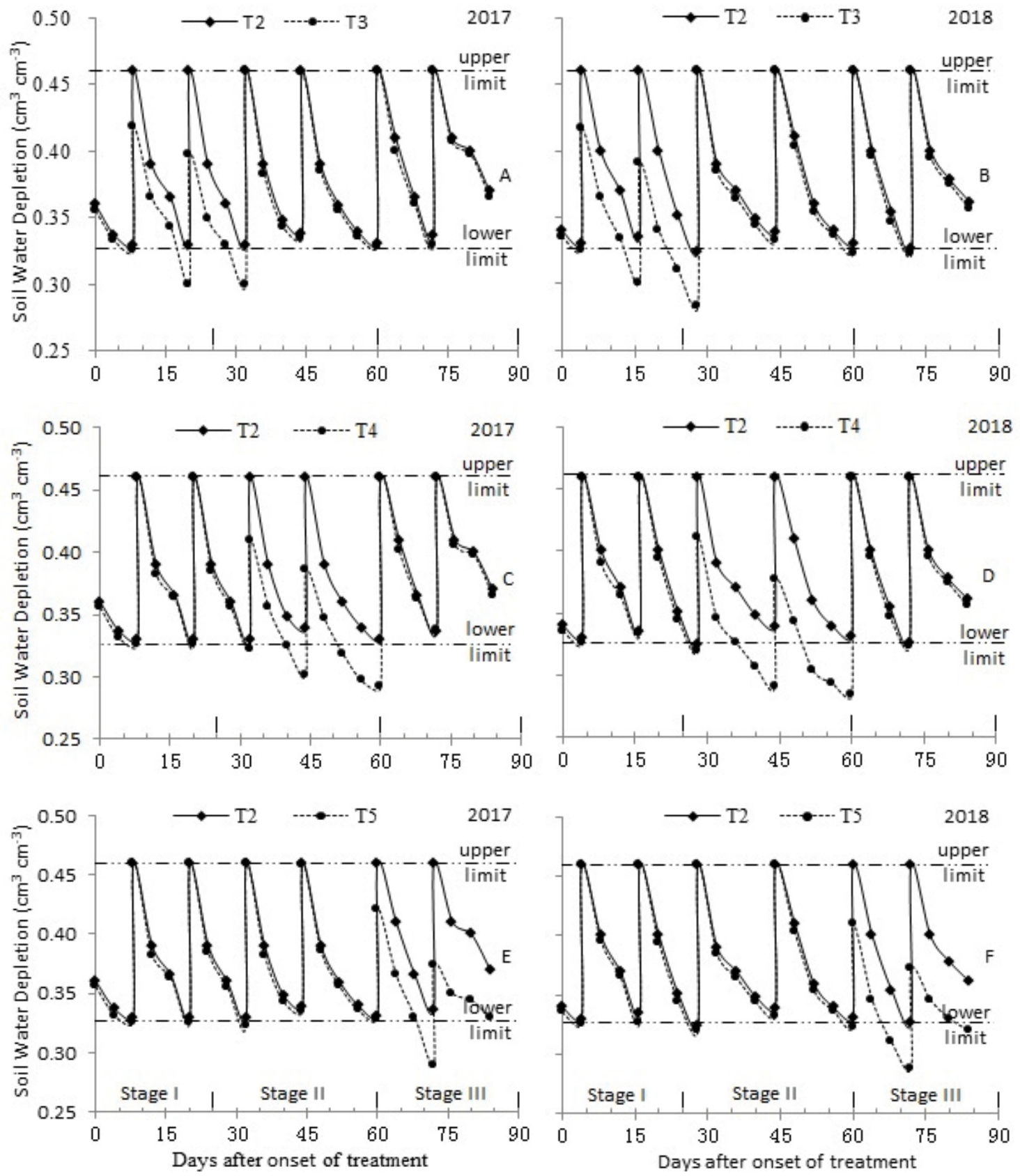

Figure 3. Trends of soil water depletion $(0-30 \mathrm{~cm}$ depth) of deficit irrigation treatments (T3-T5) and the fully irrigated treatment (T2) during the cropping cycle in the 2017 (A, C, E) and 2018 (B, D, F) seasons. All the treatments included biochar at $10 \%$ by weight. For additional explanations, see Fig. 2 
Table 2. Effects of biochar and irrigation regime on crop water use (ET), total fruit yield and water use efficiency (WUE) of tomato in 2017 and 2018 seasons

\begin{tabular}{lcccc}
\hline Cropping season & Treatment & $\begin{array}{c}\text { ET } \\
(\mathrm{mm})\end{array}$ & $\begin{array}{c}\text { Total yield } \\
(\mathrm{t} \mathrm{ha})^{-1}\end{array}$ & $\begin{array}{c}\text { WUE } \\
\left(\mathrm{kg} \mathrm{m}^{-3}\right)\end{array}$ \\
\hline \multirow{4}{*}{2017} & T1 & $502.32 \mathrm{a}$ & $141.94 \mathrm{~b}$ & $28.26 \mathrm{c}$ \\
& T2 & $455.67 \mathrm{~b}$ & $160.72 \mathrm{a}$ & $35.27 \mathrm{a}$ \\
& T3 & $438.54 \mathrm{c}$ & $143.22 \mathrm{~b}$ & $32.66 \mathrm{~b}$ \\
& T4 & $436.16 \mathrm{c}$ & $104.60 \mathrm{~d}$ & $23.98 \mathrm{~d}$ \\
& T5 & $432.11 \mathrm{c}$ & $124.53 \mathrm{c}$ & $28.82 \mathrm{c}$ \\
\hline \multirow{3}{*}{2018} & T1 & $516.30 \mathrm{a}$ & $139.09 \mathrm{~b}$ & $33.41 \mathrm{c}$ \\
& T2 & $458.70 \mathrm{~b}$ & $153.26 \mathrm{a}$ & $30.58 \mathrm{~b}$ \\
& T3 & $449.73 \mathrm{c}$ & $137.51 \mathrm{~b}$ & $25.60 \mathrm{c}$ \\
\hline
\end{tabular}

$*$ WUE $=$ Total yield/ET. Columns with the same letter represent values that are not significantly different at the 0.05 level of probability according to the LSD test. Each value is the mean $(n=3)$. The treatment symbols are the same as in Table 1

significant $(p<0.05)$. With regard to the deficit irrigation treatments, the adverse effect of water stress on yield was minimal at the vegetative stage. Compared with treatment $\mathrm{T} 2$, the total fruit yield for treatments T4 and T5 was reduced by $35.2 \%$ and $22.5 \%$ for the 2017 season, and by $25.6 \%$ and $21.7 \%$ for the 2018 season, respectively.

The effect of biochar and different irrigation regimes on water use efficiency (WUE) followed a similar trend for both seasons (Tab. 2). The highest WUE of $35.3 \mathrm{~kg} \mathrm{~m}^{-3}$ was obtained for the T2 treatment and the lowest of $23.98 \mathrm{~kg} \mathrm{~m}^{-3}$ was obtained for the T4 treatment for the 2017 season. Despite having the same irrigation regime, the water use efficiency of treatment $\mathrm{T} 2$ was significantly different from that of the control $(p<0.05)$. Relative to treatment T2, the water use efficiency of treatments T3, T4 and T5 was reduced by $7.4 \%, 32.1 \%$, and $18.3 \%$ for the 2017 season, while for the 2018 season it was reduced by $8.4 \%, 23.4 \%$, and $16.3 \%$, respectively.

\section{External quality attributes and their response to different treatments}

The overall external quality parameters followed a similar trend in both growing seasons. The fruit shape index showed no significant difference ( $p>$ 0.05 ) among the treatments (Fig. 4A), and this can be attributed to the genetic qualities of the cultivar. The colour index (CI) increased with a decrease in water availability along the phenological stages, with treatment $\mathrm{T} 5$ producing redder fruits in both seasons (Fig. 4B). Treatment T2 resulted in the highest fruit weight, with treatments $\mathrm{T} 4$ and $\mathrm{T} 5$ producing the smallest fruits (Fig. 4D). In the 2017 season, the volume per fruit for the fully irrigated treatment $\mathrm{T} 2$ was significantly higher than that for the deficit irrigation treatments at stages II and III. In the 2018 season, treatment T3 resulted in the highest value of volume per fruit, but the statistical difference was not significant $(p>0.05)$ relative to treatment T2 (Fig. 4C).

\section{Taste and nutritional quality attributes and their response to different treatments}

The values of TSS, VC and SAR increased significantly at growth stages II and III (Fig. 5A, $5 \mathrm{~B}, 5 \mathrm{C})$. The values of $\mathrm{VC}$ were increased by the limitations in water supply, particularly at the last two growth stages in both seasons. When compared with treatment $\mathrm{T} 2$, the $\mathrm{VC}$ content in treatments $\mathrm{T} 4$ and $\mathrm{T} 5$ showed an increase of $13.6 \%$ and $21.6 \%$ in the 2017 season and $36.6 \%$ and $40.1 \%$ in the 2018 season, respectively. The concentration of $\mathrm{OA}$ was high at the vegetative stage, as opposed to the other phenological stages in the deficit irrigation treatments, and this trend was similar in both seasons (Fig. 5D). The sugar/acid ratio increased significantly in the deficit irrigation treatments mainly in treatments T4 and T5; however, higher values of sugar/acid ratios were obtained in the 2017 season.

\section{Comprehensive quality index and treatment rankings}

The results show that the comprehensive quality index rankings of the different treatments were almost the same in both seasons as determined by the TOPSIS analysis method. The highest values of the comprehensive quality index determined by TOPSIS were recorded in treatment T5 at 0.597 and 0.615 , while the lowest values were obtained 

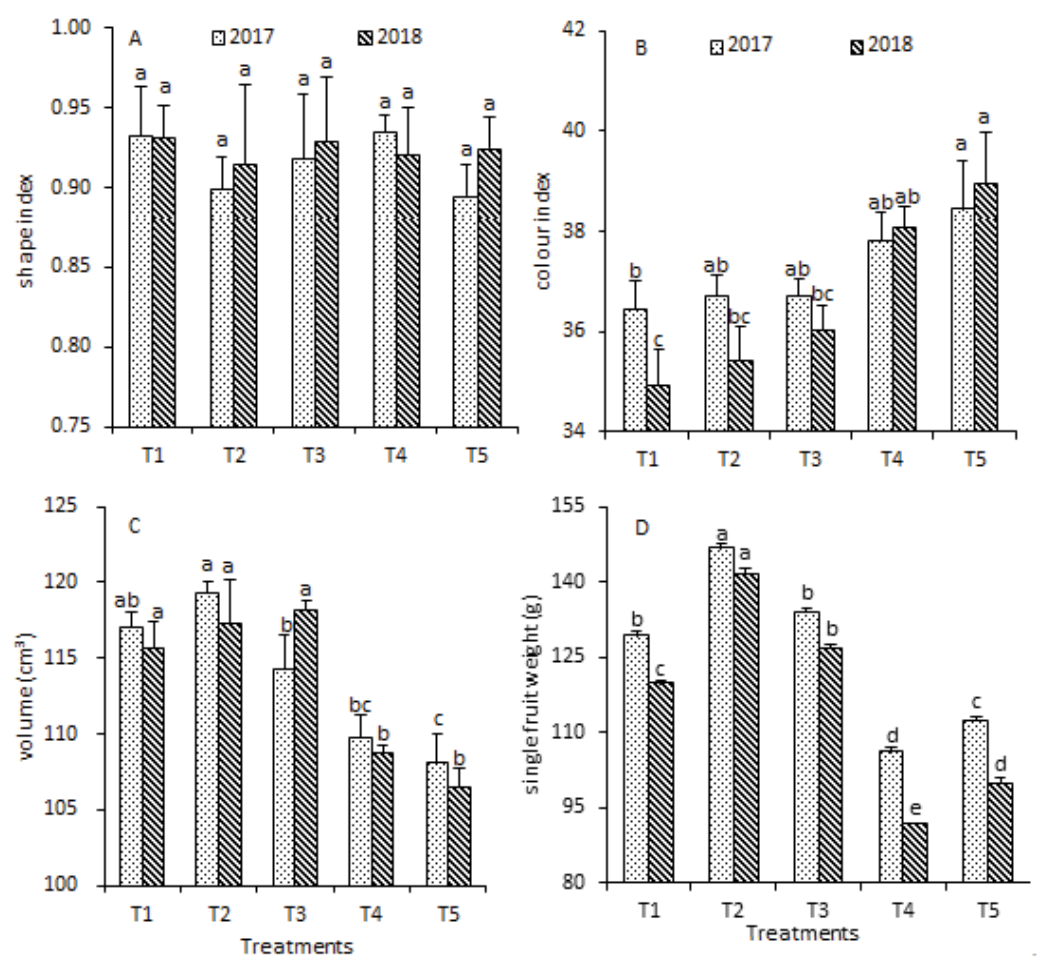

Figure 4. Effects of biochar and different irrigation treatments on the external quality attributes of tomato fruit in the 2017 and 2018 seasons. Columns with the same letter represent values that are not significantly different at the 0.05 level of probability according to the LSD test. The treatment symbols are the same as in Table 1
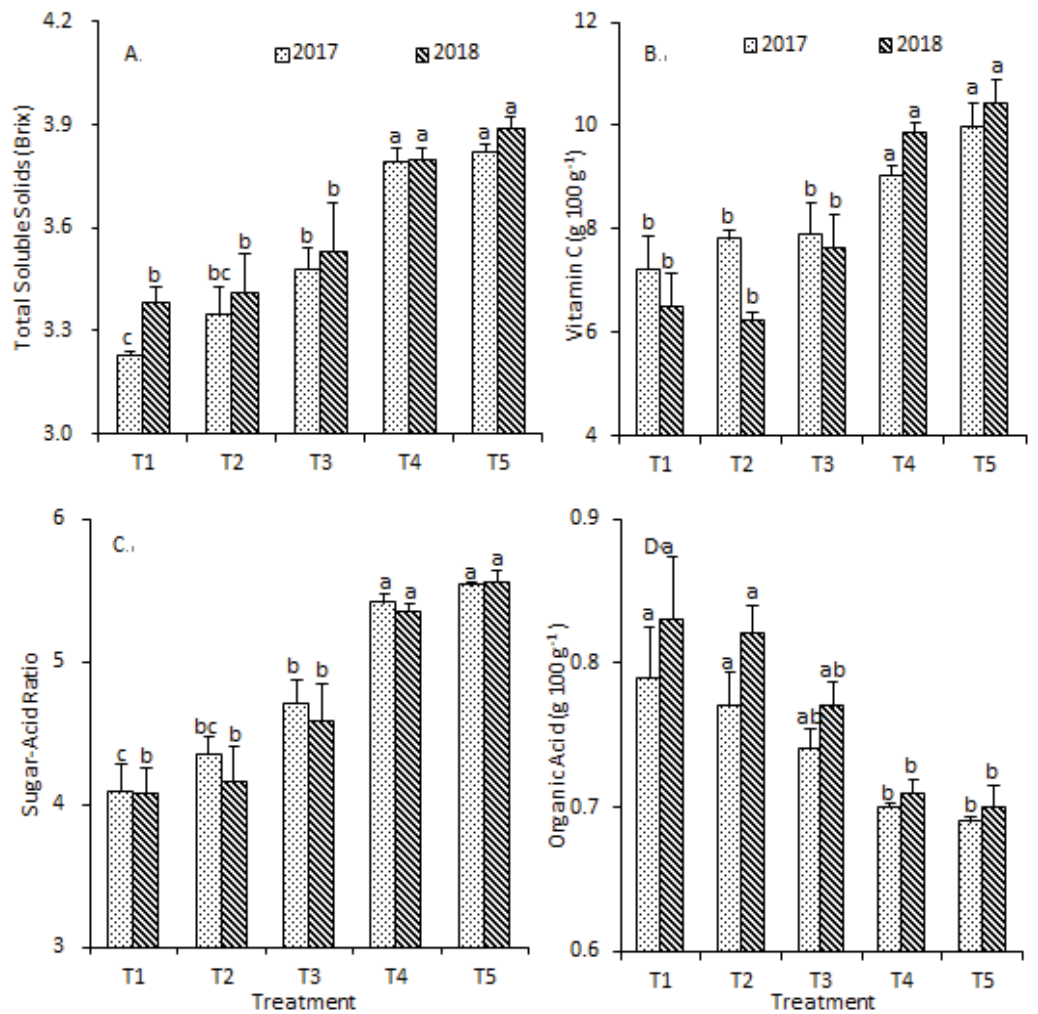

Figure 5. Effects of biochar and different irrigation treatments on taste quality attributes (Total Soluble Solids (A); Sugar-Acid Ratio (C); Organic Acid (D)) and nutritional quality (Vitamin C (B)) attribute of tomato fruit in the 2017 and 2018 seasons. Columns with the same letter represent values that are not significantly different at the 0.05 level of probability according to the LSD test. The treatment symbols are the same as in Table 1 


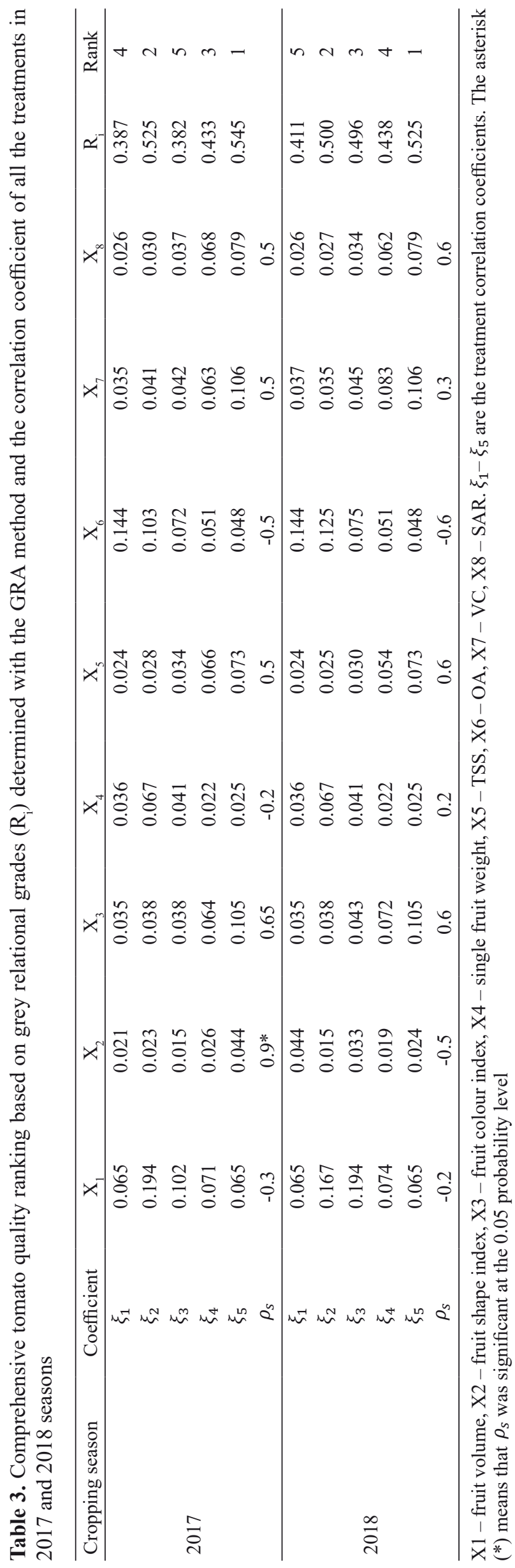

in treatment $\mathrm{T} 1$ at 0.345 and 0.337 in the 2017 and 2018 seasons, respectively (Tab. 4). Referring to the results of the GRA method, the ranking pattern was different in both seasons, with treatments T3 and $\mathrm{T} 1$ producing the lowest values in the 2017 and 2018 seasons, respectively (Tab. 3). It is evident that treatment T5 is the best, as it ranked number one in both growing seasons across all the evaluation methods, including the combinational evaluation method as presented in Table 5 .

The Spearman correlation analysis was conducted between the rankings of single quality traits and the comprehensive quality index in order to recognize the rationality of the comprehensive quality index in assessing the overall tomato quality performance of the different treatments. The number of positive correlation coefficients constituted $62.5 \%$ of the total for the GRA method in both seasons. In respect of the TOPSIS method, the number of negative coefficients constituted $37.5 \%$, whereas positive coefficients constituted $75 \%$ of the total in the 2017 season. In the 2018 season, however, positive and negative coefficients had a an equal $50.0 \%$ share each.

\section{DISCUSSION}

Biochar has been widely reported for its complementary properties able to improve soil chemical and physical properties, with the primary aim of improving crop growth and yield. It is apparent that adding biochar to the soil increased its moisture retention capacity. As a result, crop productivity and proportionality of WUE to fruit yield in treatment T2 increased significantly in comparison with treatment T1. Our findings are corroborated by Agbna et al. (2017), who revealed that roughly $25 \%$ less water was needed when biochar was applied to the soil to obtain yields comparable to those produced in ordinary soils. Many studies have reported that the deficit irrigation strategy in tomato leads to lower yields (Topcu et al., 2007; Jensen et al., 2010). In our study, the yield reduction percentage was minimal in treatment $\mathrm{T} 3$, and the negative effect of deficit irrigation on fruit yield was manifested in the last two growth stages, with the flowering and fruiting stage being the most sensitive stage.

Fruit appearance is the foremost quality trait to consumers (Labate et al., 2007), and it is usually based on the size, shape and redness of the fruit. The reduced water supply proved to have a significant effect on fruit size, more precisely the weight. The difference in fruit weight can be attributed 


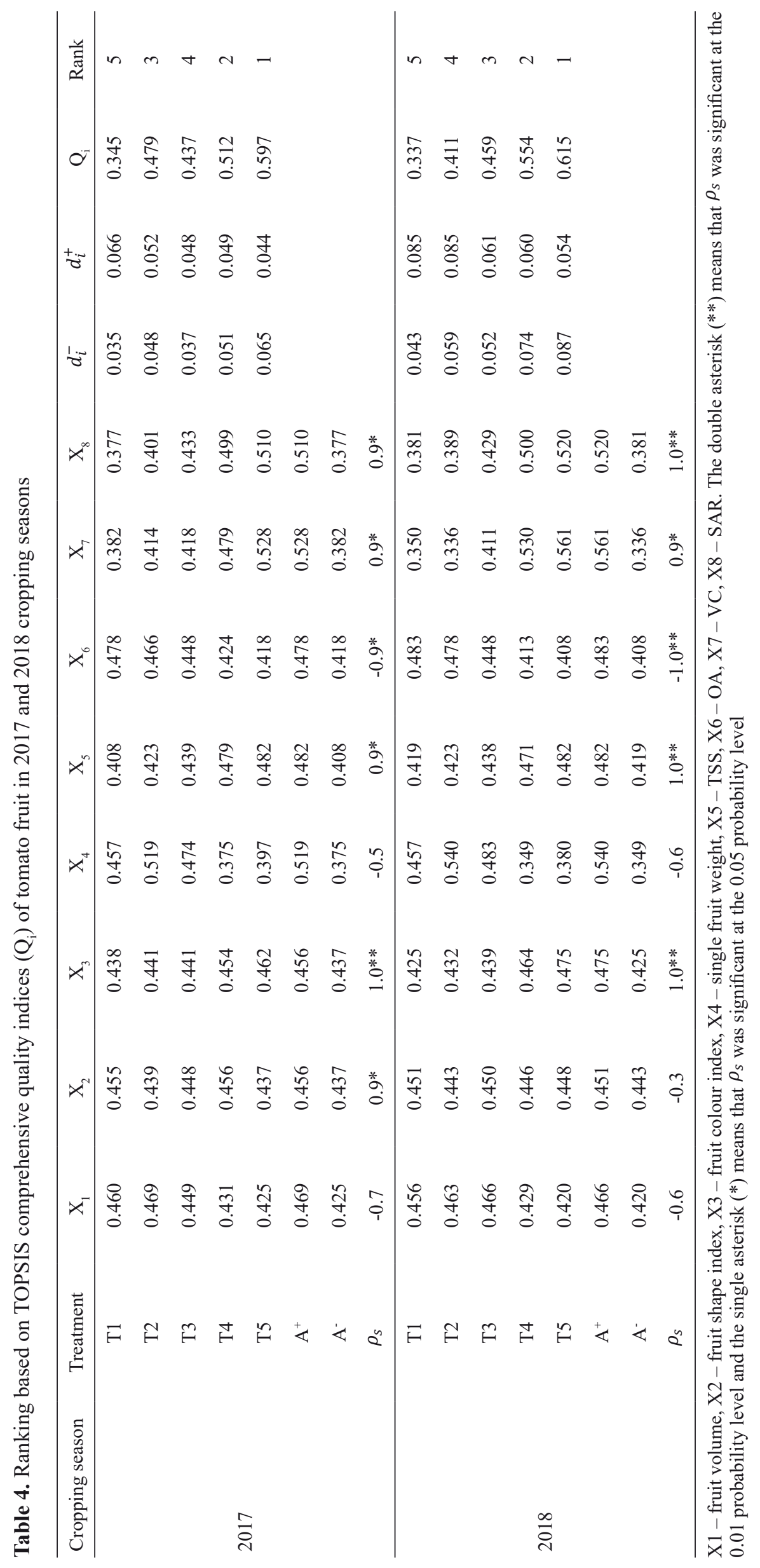


Table 5. Overall ranking of treatments based on the combinational value $\left(\mathrm{C}_{\mathrm{i}}\right)$ of comprehensive quality indices analyzed with the combinational evaluation method for 2017 and 2018 seasons

\begin{tabular}{|c|c|c|c|c|}
\hline \multirow{2}{*}{ Treatments } & \multicolumn{2}{|c|}{2017} & \multicolumn{2}{|c|}{2018} \\
\hline & $\mathrm{C}_{\mathrm{i}}$ & Rank & $\mathrm{C}_{\mathrm{i}}$ & Rank \\
\hline $\mathrm{T} 1$ & 0.364 & 5 & 0.368 & 5 \\
\hline $\mathrm{T} 2$ & 0.500 & 2 & 0.448 & 4 \\
\hline $\mathrm{T} 3$ & 0.412 & 4 & 0.474 & 3 \\
\hline $\mathrm{T} 4$ & 0.476 & 3 & 0.506 & 2 \\
\hline T5 & 0.573 & 1 & 0.577 & 1 \\
\hline \multirow[b]{2}{*}{$w_{k}$} & GRA & TOPSIS & GRA & TOPSIS \\
\hline & 0.46 & 0.54 & 0.42 & 0.58 \\
\hline
\end{tabular}

$*_{\mathrm{W}_{\mathrm{k}}}$ is the weight computed from the ratio of the Spearman correlation coefficient of each method

to water stress, in particular the growth stage, intensity and the period at which the stress occurs (Cantore et al., 2016); this is in accordance with our findings. Smaller fruits were obtained when deficit irrigation was applied at the flowering and fruiting stage, followed by the ripening stage. If the evapotranspiration of the crop is greater than the water supply, the rate at which roots absorb water will be lessened, which triggers an internal water deficiency affecting photosynthesis, resulting in intercellular volume and cell size reduction, as well as reduced accumulation of fruit water content and consequently a decrease in fruit weight (Madrid et al., 2009; Wang et al., 2011).

In this study, the tomato fruit shape indices were similar and there were no statistical differences among the treatments, which suggests that fruit shape was mainly influenced by the genetic qualities of the cultivar (Shao et al., 2015) rather than the biochar amendment or deficit irrigation. Water stress increases the redness of tomato fruits (Wang et al., 2011). The red colour is primarily associated with the presence of lycopene and is considered the paramount quality attribute determining fruit ripeness as well as presenting an appealing appearance to the consumer (Nangare et al., 2016). We observed that the water supply limitation during the fruit ripening stage promoted a significant increase in the colour index, just like the preceding findings that the colour index was positively affected by water stress applied at the fruit growth and ripening stages (Nuruddin et al., 2003). This is due to the fact that water stress raises tomato ethylene content, consequently increasing the lycopene content and carotenoid concentration, thus making the pericarp of the tomato fruit redder (Basiouny et al., 1994).

The nutritional quality and taste of the tomato fruit is mainly determined by the sugar-acid ratio and VC content (Dorais et al., 2001). It has been widely reported that deficit irrigation enhances these quality traits (Chen et al., 2013). This fact was corroborated by the results presented in this study, showing that the concentration of TSS increased with water stress in the last two growth stages. This may be associated with an increase in the activities of sucrose synthase and phosphate syntheses under water stress (Qi et al., 2003), which may also increase the rate and amount of fructose and glucose transformation from sucrose (Kan, 2008). The study by Agbna et al. (2017) demonstrated that adding biochar to the soil increased total nitrogen relative to treatments without it. Increasing nitrogen doses enhances the photosynthetic rate, leading to increased production of photosynthates, which may be stored as reducing sugars in tomato fruits (Wang et al., 2007). The VC content was enhanced by water limitation, but no significant effect was observed in relation to biochar amendment. However, it should be noted that the level of VC content in vegetables is influenced by many factors, among them the level of maturity, cultivar and crop nutrition other than irrigation management (Antonio et al., 2007).

In many instances, evaluating fruit quality is not an easy task as it solely concerns consumer perceptions and preferences. The GRA and TOPSIS appraisals were used to evaluate the best comprehensive quality index and the combinational evaluation method to determine the ideal rank. It is evident from the results that of all the Spearman correlation coefficients that were determined 59.4\% were positive, demonstrating a proper fit between the rank of the comprehensive quality index and that of most of the single quality attributes. There were also negative correlations obtained, and this might be explained by the inverse proportion these 
attributes had on water stress, while other attributes were increased by the same effect.

To meet the requirement of irrigation management and strategy for high-quality tomato production, not only fruit quality parameters but also fruit yield should be considered. Although the strategy of deficit irrigation at stages II and III improved most of the single quality attributes, it presented risks of jeopardizing fruit yield through reduced single fruit weight and volume. In fact, in the interest of producers, the strategy would be to guarantee the sustainability of fruit yield and also to improve the acceptable levels of quality and water use efficiency. Taking into consideration this interest, more reasonable water management with a better compromise between yield and quality in tomato production should be investigated in order to optimize the quantitative relationship between tomato yield, fruit quality and water consumption.

\section{CONCLUSIONS}

In summary, applying the biochar amendment improved soil moisture conservation, which contributed positively to fruit yield (treatment T2). The comprehensive quality analysis proved that deficit irrigation strategy at the fruit ripening stage yielded the best overall fruit quality, while fruit yield was the most sensitive to water stress during the flowering and fruiting stage. In this study, there was only one level of biochar amendment and water stress during the different plant developmental stages. Therefore, additional experiments with different degrees of water stress and biochar amendment should be conducted to determine potential responses.

\section{ACKNOWLEDGEMENT}

The authors extend their gratitude to the National Nature \& Science Foundation of China, the Program of the Postgraduate Research "Jiang Su Qing Lan" and the project of the Priority Academic Program Development of Jiangsu Higher Education Institutions for supporting this project.

\section{FUNDING}

This work was funded by a key program granted by the National Nature \& Science Foundation of China (No. 51279059) and supported by "Jiang Su Qing Lan", and the project "the Priority Academic Program Development of Jiangsu Higher Education Institutions".

\section{AUTHOR CONTRIBUTIONS}

L.K., J.C. and G.S. - formulated the overarching research goals and aims; L.K., J.C. and J.L. collected the data and maintained the research data for initial use and later reuse; L.K., J.C. and G.S. - developed or designed the methodology; L.K. and J.C. - applied statistical and computational techniques to analyze the study data; L.K., J.C., G.S. and T.S. - created and/or prepared the manuscript, specifically writing the initial draft, critical review, commentary and revision.

\section{CONFLICT OF INTEREST}

Authors declare no conflict of interest.

\section{REFERENCES}

Agbna G.H.D., She D., Liu Z., Elshaikh N.A., ShaO G., Timm L.C., 2017. Effects of deficit irrigation and biochar addition on the growth, yield, and quality of tomato. Sci. Hortic. 222, 90-101.

Antonio J.P., Francisco M.A., Ana S.M., Maria I.F., ESTRELLA D., 2007. Influence of agricultural practices on the quality of sweet pepper fruits as affected by the maturity stage. J. Sci. Food Agric. 87, 2075-2080.

Basiouny F.M., Basiouny K., Maloney M., 1994. Influence of water stress on abscisic acid and ethylene production in tomato under different PAR levels. J. Hort. Sci. Biotech. 69, 535-541.

Cantore V., LechKar O., Karabulut E., Sellami M.H., Albrizio R., BoARI F., ET AL., 2016. Combined effect of deficit irrigation and strobilurin application on yield, fruit quality and water use efficiency of "cherry" tomato (Solanum lycopersicum L.). Agr. Water. Manage. 167, 53-61.

Chen J., Kang S., Du T., Qiu R., Ping G., Chen R., 2013. Quantitative response of greenhouse tomato yield and quality to water deficit at different growth stages. Agr. Water Manage. 129, 152-162.

Dorais M., Papadopoulos A., Gosselin A., 2001. Greenhouse tomato fruit quality. Hortic. Rev. 26, 239-319.

Djurovic N., Cosic M., Stricevic R., Savic S., Domazet M., 2016. Effect of irrigation regime and application of kaolin on yield, quality and water use efficiency of tomato. Sci. Hortic. 201, 271-278.

Favati F., Lovelli S., Galgano F., Miccolis V., Tommaso T.D., Candido V., 2009. Processing tomato quality as affected by irrigation scheduling. Sci Hortic. 122, 562-571.

Jensen C.R., Battilani A., Plauborg F., Psarras G., Chartzoulakis K., Janowiak F., et al., 2010. Deficit irrigation based on drought tolerance and root signalling in potatoes and tomatoes. Agr. Water Manage. 98, 403-413. 
KAN I., 2008. Yield quality and irrigation with saline water under environmental limitations: the case of processing tomatoes in California. Agr. Econ. 38, 5766.

Labate J.A., Grandillo S., Fulton T., Munos S., Caicedo A., Peralta I., 2007. Tomato. In: Genome Mapping and Molecular Breeding in Plants: Vegetables. C. Kole (Ed.), Springer, New York, USA, $5,1-125$.

Liu Z., Chen X., Jing Y., Li Q., Zhang J., Huang Q., 2014. Effects of biochar amendment on rapeseed and sweet potato yields and water stable aggregate in upland red soil. Catena. 123, 45-51.

Madrid R., Barba E.M., SÁnchez A., García L.A., 2009. Effects of organic fertilisers and irrigation level on physical and chemical quality of industrial tomato fruit (cv. Nautilus). J. Sci. Food Agric. 89, 2608-2615.

Nangare D.D., Singh Y., Kumar P.S., Minhas P.S., 2016. Growth, fruit yield and quality of tomato (Lycopersicon esculentum Mill.) as affected by deficit irrigation regulated on phenological basis. Agr. Water Manage. 171, 73-79.

Nuruddin M.M., Madramootoo C.A., Dodds G.T., 2003. Effects of water stress at different growth stages on greenhouse tomato yield and quality. HortScience 38, 1389-1393.

PAn G., Lin Z., Zhang A., Zheng J., Zhang X., 2011. Perspective on biomass carbon industrialization of organic waste from agriculture and rural areas in China. J. Agric. Sci. Technol. 13, 75-82 (in Chinese with English abstract).

Qi H.Y., Li T.L., Zhang J., Wang L., ChEN Y.H., 2003. Effects on sucrose metabolism, dry matter distribution and fruit quality of tomato under water deficit. Agr. Sci. China. 2, 1253-1258.

Shao G.C., Deng S., Liu N., Wang M.H., She L.D., 2015a. Fruit quality and yield of tomato as influenced by rain shelters and deficit irrigation. J. Agri. Sci. Tech. 17, 691-704.
Steiner C., Teixeira W.G., Lehmann J., Nehls T, de Macedo J.L.V., Blum W.E.H., et AL., 2007. Long term effects of manure, charcoal and mineral fertilization on crop production and fertility on a highly weathered Central Amazonian upland soil. Plant Soil 291, 275-290.

Topcu S., Kirda C., Dasgan Y., Kaman H., Cetin M., YAZICI A., BACON M.A., 2007. Yield response and $\mathrm{N}$-fertilizer recovery of tomato grown under deficit irrigation. Eur. J. Agron. 26, 64-70.

Usman A.R.A., AL-Wabel M.I., Abdulaziz A.H., Mahmoud W.A., EL-Naggar A.H., Ahmad M., ET AL., 2016. Conocarpus biochar induces changes in soil nutrient availability and tomato growth under saline irrigation. Pedosphere 26, 27-38.

Wang Y.T., Huang S.W., LiU R.L., Jin J.Y., 2007. Effects of nitrogen application on flavor compounds of cherry tomato fruits. J. Plant Nutr. Soil Sc. 170, 461-468.

WANG F., 2011. Response of greenhouse tomato yield and quality to water stress and the irrigation index for water saving \& fruit quality improving. Doctoral dissertation, China Agricultural University, Beijing, China.

Wang F., Kang S.Z., Du T.S., Li F.S., QIU R.J., 2011. Determination of comprehensive quality index for tomato and its response to different irrigation treatments. Agric. Water Manag., 98, 1228-1238.

Wang C., Gua F., Chena J., Yanga H., Jiangb J., Dua T., ET AL., 2015. Assessing the response of yield and comprehensive fruit quality of tomato grown in greenhouse to deficit irrigation and nitrogen application strategies. Agr. Water Manage. 161, 9-19.

Warnock D.D., Lehmann J., KuyPer T.W., Rillig M.C., 2007. Mycorrhizal responses to biochar in soilconcepts and mechanisms. Plant Soil 300, 9-20.

ZHU B., XU Z.S., 2014. Analytic hierarchy processhesitant group decision making. Eur. J. Oper. Res. 239, 794-801.

Received October 1, 2018; accepted December 6, 2018 